\title{
Critique of the Linear-Compensatory Approach in Customer Satisfaction Measurement: An Empirical Study
}

\author{
Pushkal Kr. Pandey ${ }^{1}$, Sandra Moffett ${ }^{2}$, Rodney McAdam ${ }^{2}$ \\ ${ }^{1}$ Woxsen School of Business, Hyderabad, India \\ ${ }^{2}$ University of Ulster, Jordanstown, UK \\ Email: Pushkal.p@woxsen.edu.in
}

How to cite this paper: Pandey, P.K., Moffett, S. and McAdam, R. (2019) Critique of the Linear-Compensatory Approach in Customer Satisfaction Measurement: An Empirical Study. Theoretical Economics Letters, 9, 1210-1224. https://doi.org/10.4236/tel.2019.94078

Received: February 25, 2019

Accepted: April 27, 2019

Published: April 30, 2019

Copyright $\odot 2019$ by author(s) and Scientific Research Publishing Inc. This work is licensed under the Creative Commons Attribution International License (CC BY 4.0).

http://creativecommons.org/licenses/by/4.0/ (c) (i) Open Access

\begin{abstract}
Purpose of the Study: The researchers critique the linear-compensatory combinatorial rule used in the expectancy-value model that is widely applied to explain how customers integrate attribute-level information in satisfaction judgements. Data/Methodology: The data have been collected from customers of an online travel agency. The surveys were administered via email, after their interaction with customer service advisor on telephone. The survey instrument is largely based on the SERVQUAL model, with a few additional items pertaining to the call centre context. A randomly selected sample of 626 usable responses was obtained based on completeness of data. As compared to the traditional methods, where a summary analysis of aggregated data is done, the present data analysis follows a deconstructive approach, involving assessing changes in degree of satisfaction brought about by change in each degree of performance for every quality attribute. Findings: By following a unique analytical approach to analysing survey data, the study classifies customer satisfaction as not unlike other evaluative judgements, such as morality and likableness, where summary evaluations are a result of a cumulative assessment of all attributes that constitute the particular context. Originality: This study explores the process of cognitive appraisal, which underlies the combination of varied service quality information, in the form of attributes of service quality into unitary satisfaction judgements.
\end{abstract}

\section{Keywords}

Service Quality, Customer Satisfaction Measurement, Linear Regression Model, Information Integration Theory 


\section{Introduction}

Consumer research is primarily driven by the quest to understand the judgement process of an individual [1]. A major application of this stream of research has focussed on how customers' process information on performance of quality attributes, to form summary evaluative judgements, as satisfaction/dissatisfaction. [2] tried to answer a similar question, in analysing how people form a certain impression of a person's character from a complex pattern of traits and behaviours. He concluded that, to understand how personality impressions are formed, the effect of the various traits and behaviours should be seen in relation to the overall evaluative judgement, as well as, to one another.

Accordingly, the present study argues that in understanding how attributes of quality affect customer satisfaction, two facets of this process ought to be considered, first; the link between performance on individual attributes and the overall evaluative judgement, and second; the psychological process of combining attribute-level performance information. The following section critiques the principles that guide integration of information within the frequently applied expectancy-value model proposed by [3].

\section{Conceptual Background}

Consumer researchers have widely used the expectancy-value model, first adopted by [4], and, then made popular by [5] to explain the effect of quality attributes on customer satisfaction. [6] suggested that the attribute-level performance and overall satisfaction in the expectancy-value model, are linked through, a linear-compensatory relationship. The linearity implies that as key attribute performance scores increase, the satisfaction increases proportionally. Furthermore, a compensatory relationship means that the lower performance on an attribute can be compensated for by higher performance on other attributes. The implication being that managers may prioritise quality attributes and allocate resources to the comparatively important ones from attributes perceived as less important [7] [8] [9] [10].

This approach demonstrates an oversimplification of the attribute integration process. Mainly, since the expectancy-value model focuses on one form, where the overall attitude is a multiplicative product of scale value in form of performance ratings and weight/importance of the attribute to the customer, summed over the relevant attributes. The following equation represents performance assessment in form of expectancy-value model, with reference to service delivery in a call centre:

$A S_{\text {qual }}=S_{\text {noc }} W_{\text {noc }}+S_{q t i m} W_{q t m}+S_{\text {frd }} W_{\text {frd }}+S_{\text {emp }} W_{\text {emp }}+S_{\text {rel }} W_{\text {rel }}+S_{\text {ass }} W_{\text {ass }}+S_{\text {qrest }} W_{\text {qrest }}$

Equation (1) says that a customer's overall attitude of satisfaction/dissatisfaction with the service delivery in a call centre $\left(\mathrm{AS}_{\text {qual }}\right.$ measured in terms of degree of satisfaction/dissatisfaction, expressed on a likert scale) equals, or is a function of the linear addition of the products of service representatives performance on the mentioned quality attributes (for example, $S_{\text {rel }}$ is the customer's judgement about customer service representatives performance on reliability aspect of service, 
measured on a 5-point scale from "completely satisfied" to "completely dissatisfied"), and customers' appraisal of how important those attributes are for the customer (for example, $\mathrm{W}_{\text {rel }}$ is customers' evaluations of how important reliability of customer service representative is), in the current context of service. The attributes mentioned in the equation are noc $=$ number of contacts, qtim $=$ queue time, frd $=$ friendliness, emp $=$ empathy, rel $=$ reliability, ass= assurance, qrest $=$ query resolution time.

Here, the weights $W_{\text {values }}$ are assumed to be independent of the scale values $S_{\text {values }}$ and, the effect of each attribute is independent of the other attributes with which it is combined [11]. Furthermore, the overt judgemental response, represented as $A S_{\text {quab }}$ is assumed to be a monotonic transformation of the psychological values (i.e. the multiplicative product of the scale value and weight/importance of the attribute) of the stimuli [12]. It is this assumption that allows the use of an additive mathematical model, such as analysis of variance on overt judgmental response in determining the effect of attributes to form satisfaction/dissatisfaction judgment.

However, when we look at how impressions of morality or likableness of an individual are formed, a deviation from such additive models of information integration is found [12]. In a series of articles, Birnbaum and his colleagues [12]-[17] suggest that the impressions of morality or likableness are not formed by combining information as simple sums of constant-weights, of the separate values of the traits/deeds. [16] found that performance of very immoral deeds limits the highest level of morality a person can achieve, although, the value of that limit appeared to depend upon both the immorality of the bad deeds and the virtue of the good ones.

To facilitate understanding of how personality judgements are formed from the observed traits and behaviours, [18] propose that a judgement should be conceived as a composition of functions. For example, in case of judgements based on single piece of information, like weight estimation, the psychological value of the stimulus is related to the physical value by a single psychological function. In case of complex judgements, like forming the impression of a person, the subjective values of the stimuli/attributes are a result of process involving interaction between several psychological functions. The set of stimuli/attributes together form a context. In forming a personality-related impression, [2] argued that, within a given set of traits, some take a more central role than others and that these "set the direction for the further view of the person." Therefore, summary evaluations are guided by the context of the stimuli/attributes, although, the contexts are dominated by a particular locus [19]. That is, there are one or few dominant stimuli that drive the overall impression formation, but the overall impression is a function of all the stimuli in the context.

\section{Hypothesis}

The current study aligns with the above theory on how impressions of morality 
are formed and extends it to attempt to explain how customers evaluate quality. This leads us to the following hypothesis for evaluations of quality with respect to an overall degree of satisfaction:

$\mathrm{H}^{1}$ : a customer does not hold the weight/importance of the attributes as constant, but varying, with respect to performance on the attribute itself as well as performance on other attributes comprising the context for the specific kind of service/product.

Therefore, the effects of quality attributes on customer satisfaction are not independent of each other, as is assumed in the linear additive models of customer satisfaction, and as hypothesised, under the widely used expectancy-value model.

\section{Framework of Research Methodology}

Customer satisfaction has been consistently observed as comprising of a number different experiences, distinguished by arousal level and emotions involved in the customer experience [20]. [4] espoused the notion that varied response orientations are summed in the common rubric of satisfaction. As discussed by [21] customer satisfaction is not a uniform feeling, but composed of qualitatively different states of emotion, such as happy confidence or resigned agreement, dissatisfaction with disappointment and angry protest. They argue that, such varied emotions demand different adaptive responses from service personnel, as each of these emotions lead to a different customer behaviour towards the company. As such, allowing for patterns of disaggregated emotional experience under the customer satisfaction judgement, enables assessment of more complex emotional experiences, and highlights the integration mechanism, that is involved in forming different levels of satisfaction.

Such a taxonomic approach, provides a means for mapping effects of varying levels of performance on quality attributes. The patterns of consumption emotion identified in the taxonomic analysis, extend knowledge of post-service appraisal by demonstrating that a number of qualitatively different affective experiences are a result of unique underlying psychological processes of information integration on attributes of quality.

Hence, this research produces a sensitivity analysis of the propensity for customer satisfaction to vary across these levels with different combination of performance, dependent on a range of quality attributes. [22], argue that the relative importance of attributes obtained through an aggregated cross-sectional analysis of the accumulated data in customer satisfaction surveys does not necessarily represent a very close match to the cognitive information processing at any specific level of satisfaction. Therefore, analysis based on cross-sectional approach may be somewhat misrepresentative.

[23] observed that "any theoretically non-linear pattern of data can be decomposed into segments which are entirely linear", thus any non-linearity may only be noted, when the entire continuum of data is represented. Thus, although the approach to analysis of customer satisfaction survey in this paper is different 
from any prior research, it suits the objective which it has undertaken, i.e. to illustrate, how change in each degree of satisfaction is achieved using the exact manner in which attributes influence customer satisfaction.

Therefore, in the present study, rather than conducting an aggregated analysis of all survey data, different states of customer satisfaction (measured on Likert scales values of 1 - 5) are distinguished as distinct incidents of customers' affective appreciation. This approach enables the researchers to deconstruct the customer satisfaction response variable into its underlying cognitive dimensions. An innovative measurement approach is adopted, that can mirror the consumer judgement process. Such in-depth analysis is more representative of the data, enhancing its practical application.

\section{Research Context: Call Centres}

The focus of the current study is mainly methodological and interpretive. It does not claim any specialised understanding of service quality in the call centre context. Therefore, the service attributes relied on, have been derived from prior research on service quality in call centres. The service quality during customer agent interaction is typically judged based on the following attributes [24]:

1) Number of contacts-number of times, a customer had to contact customer service before his/her query was resolved.

2) Queue time-amount of time customer waited to speak to customer support agent.

3) Query resolution time-time taken for the query to be resolved

4) Friendliness-the degree to which the agent sounded friendly and professional throughout the call

5) Empathy-the agent's ability to listen and understand the reasons for customer's query

6) Assurance-the agent appeared knowledgeable and confident,

7) Reliability - the agent was able to understand and provide a solution to the customer.

These attributes formed part of a corporate customer satisfaction survey, used by a customer service department of the case call centre. The surveys were generally sent at the end of each call via email. A total of 626 customer satisfaction surveys (CSAT surveys) were randomly collected from the available database of surveys based on completeness of data. The current survey assessed performance of the service provider on a number of attributes as independent variables, and overall customer satisfaction was used as a dependent variable (both measured on a Likert scale of $1-5$ ), 5 being the most positive, whereas, 1 being the most negative. Appendix presents the questionnaire employed.

\section{Data Analysis}

In survey data analysis, it is rare to find exactly congruent values in stimulusresponse relationships, because most responses are dependent on an assessment 
of multiple factors. To identify that decline in performance at which service attribute is causing the change in a degree of satisfaction, the change in number of customers responding on all performance-levels for all attributes, will need to be mapped. Following this iterative process for change in each degree of satisfaction, going from the higher level (Level 1-Extremely satisfied) to the lowest level (Level 5-Extremely Dissatisfied) for the entire dataset of 626 responses, the below tables are derived. Straight line equations, as presented in Tables 1-4, are then used to show the changes in numbers of customers.

Figure 1, represents the data from Table 1 relating to changes in number of customers responding at different levels of performance, when the degree of customer satisfaction changes from 1 (Extremely Satisfied) to 2 (Very Satisfied). The distance of a quality attribute from median represents change in number of customers responding at that attribute. As seen in Figure 1, attributes such Friendliness, Reliability, Assurance and Empathy show the highest change in number of respondents causing degree of customer satisfaction to shift from Extremely Satisfied-Level 1 to Very Satisfied-Level 2. A detailed discussion on the meaning and interpretation of these Figures (Figures 2-4) and tables follows in the Discussion section.

Table 1. Refers to change in degree of satisfaction from level 1 (Extremely satisfied) to 2 (Very satisfied).

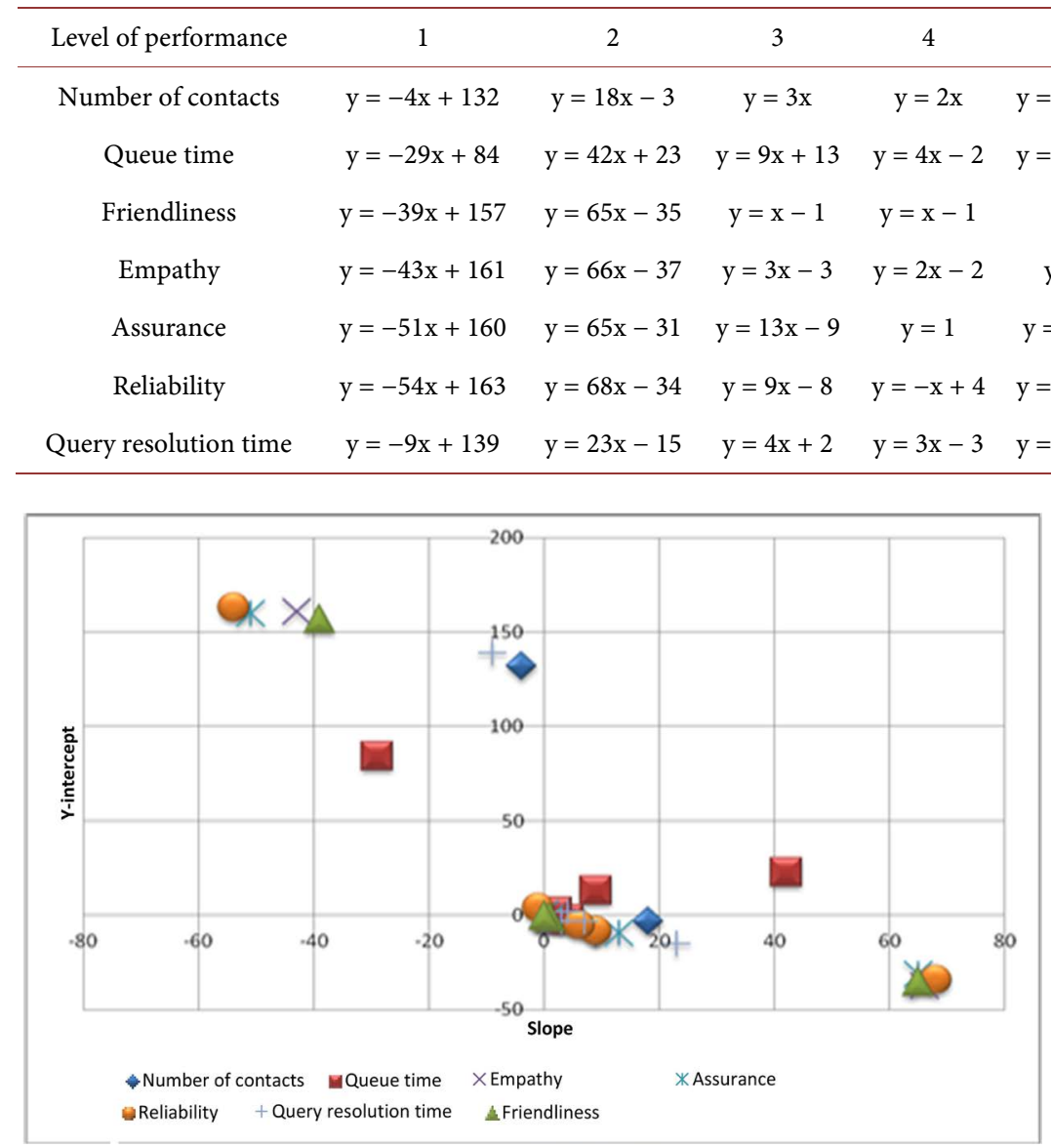

Figure 1. Scatterplot for change in degree of satisfaction from 1 to 2. 
Table 2. Refers to change in degree of satisfaction from level 2 (Very satisfied) to 3 (Satisfied).

\begin{tabular}{cccccc}
\hline Level of performance & 1 & 2 & 3 & 4 & 5 \\
\hline Number of contacts & $y=-58 x+166$ & $y=7 x+20$ & $y=5 x-1$ & $y=2 x+2$ & $y=14 x-9$ \\
Queue time & $y=-3 x+23$ & $y=-42 x+135$ & $y=7 x+17$ & $y=2 x+4$ & $y=6 x-1$ \\
Friendliness & $y=-36 x+103$ & $y=-12 x+91$ & $y=16 x-15$ & $y=2 x-1$ & 0 \\
Empathy & $y=-43 x+109$ & $y=-x+79$ & $y=10 x-8$ & $y=4 x-3$ & $y=1$ \\
Assurance & $y=-38 x+92$ & $y=-29 x+110$ & $y=24 x-12$ & $y=12 x-12$ & $y=x$ \\
Reliability & $y=-42 x+91$ & $y=-42 x+126$ & $y=41 x-33$ & $y=12 x-10$ & $y=x+4$ \\
Query resolution time & $y=-59 x+164$ & $y=-2 x+29$ & $y=8$ & $y=6 x-5$ & $y=25 x-18$ \\
\hline
\end{tabular}

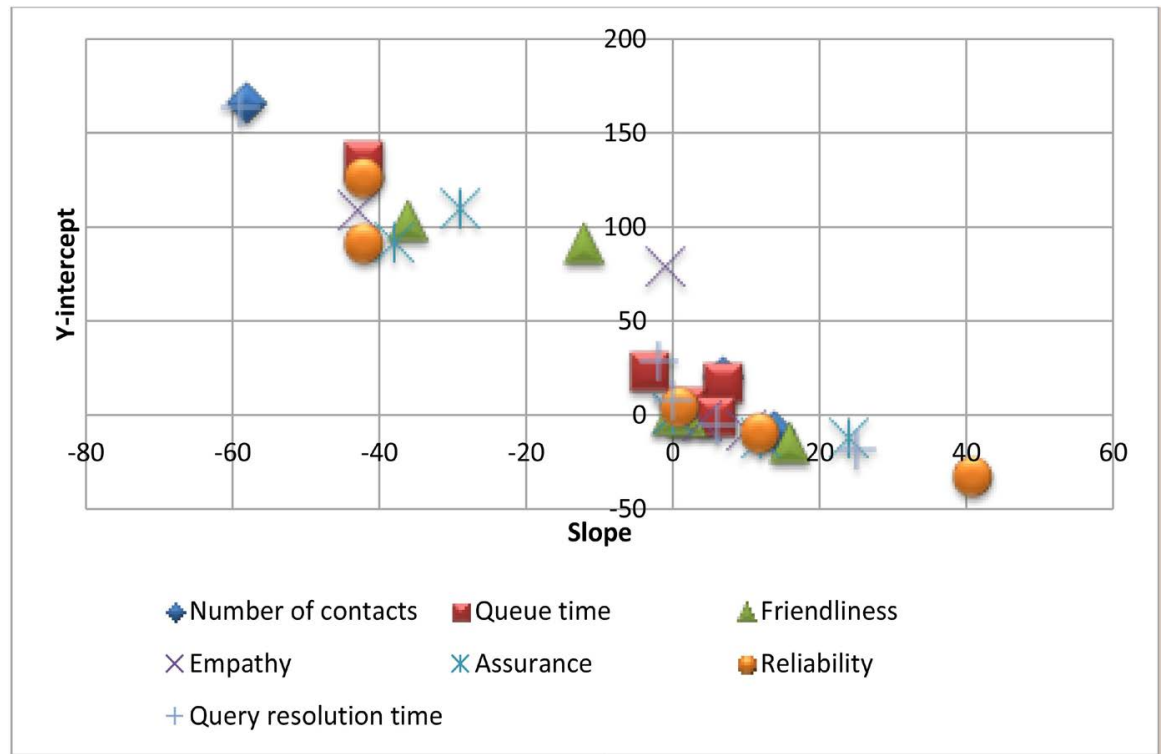

Figure 2. Scatterplot for change in degree of satisfaction from 2 to 3.

Table 3. Refers to change in degree of satisfaction from level 3 (Satisfied) to 4 (Very dissatisfied).

\begin{tabular}{cccccc}
\hline Level of performance & 1 & 2 & 3 & 4 & 5 \\
\hline Number of contacts & $y=-32 x+82$ & $y=-22 x+56$ & $y=9$ & $y=6$ & $y=33 x-14$ \\
Queue time & $y=-9 x+26$ & $y=-3 x+54$ & $y=-10 x+41$ & $y=6 x+2$ & $y=-5 x+16$ \\
Friendliness & $y=-10 x+41$ & $y=-19 x+86$ & $y=17$ & $y=6 x-3$ & $y=2 x-2$ \\
Empathy & $y=-8 x+31$ & $y=-27 x+104$ & $y=7 x+5$ & $y=4 x+1$ & $y=3 x-2$ \\
Assurance & $y=-11 x+27$ & $y=-25 x+77$ & $y=-9 x+45$ & $y=16 x-4$ & $y=8 x-6$ \\
Reliability & $y=-5 x+12$ & $y=-34 x+76$ & $y=-32 x+81$ & $y=30 x-16$ & $y=20 x-14$ \\
Query resolution time & $y=-38 x+84$ & $y=-20 x+45$ & $y=8$ & $y=3 x+4$ & $y=34 x-2$ \\
\hline
\end{tabular}

The slope and $\mathrm{y}$-intercept parameters, depicted as $\mathrm{x}$ and $\mathrm{y}$-coordinate values in the equations, show one of the following three variations:

1) Negative slope with Positive y-intercept indicates, decrease in number of people responding at that level of performance. As shown below: 


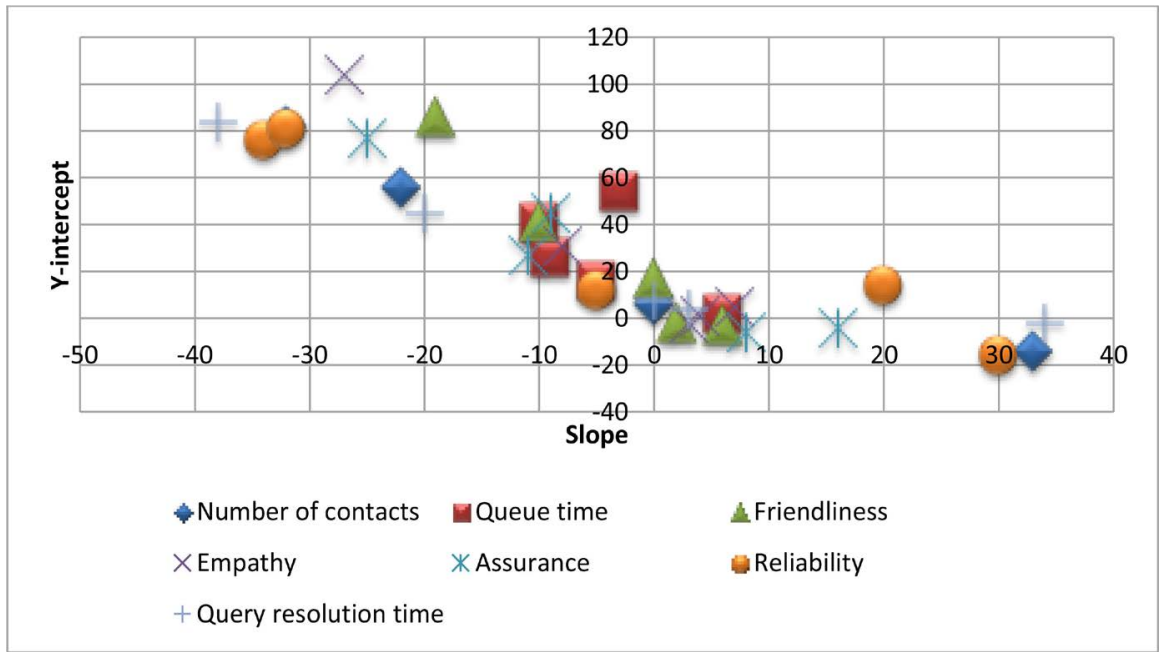

Figure 3. Scatterplot for change in degree of satisfaction from 3 to 4 .

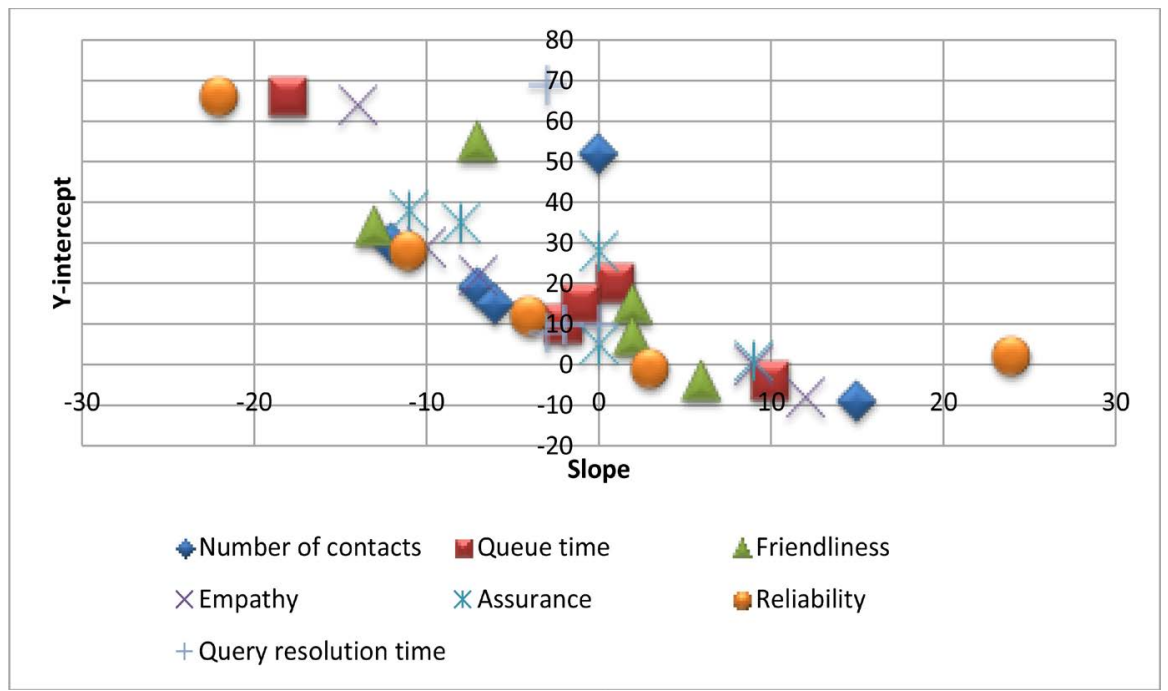

Figure 4. Scatterplot for change in degree of satisfaction from 4 to 5.

Table 4. Refers to change in degree of satisfaction from level 4 (Very Dissatisfied) to 5 (Extremely Dissatisfied).

\begin{tabular}{cccccc}
\hline Level of performance & 1 & 2 & 3 & 4 & 5 \\
\hline Number of contacts & $y=-12 x+30$ & $y=-7 x+19$ & $y=-6 x+15$ & $y=15 x-9$ & $y=52$ \\
Queue time & $y=-2 x+10$ & $y=-18 x+66$ & $y=x+20$ & $y=-x+15$ & $y=10 x-4$ \\
Friendliness & $y=-13 x+34$ & $y=-7 x+55$ & $y=2 x+15$ & $y=2 x+7$ & $y=6 x-4$ \\
Empathy & $y=-7 x+22$ & $y=-14 x+64$ & $y=-10 x+29$ & $y=9 x$ & $y=12 x-8$ \\
Assurance & $y=5$ & $y=-8 x+35$ & $y=-11 x+38$ & $y=28$ & $y=9 x+1$ \\
Reliability & $y=3 x-1$ & $y=-4 x+12$ & $y=-11 x+28$ & $y=-22 x+66$ & $y=24 x+2$ \\
Query resolution time & $y=-2 x+10$ & $y=-3 x+8$ & $y=-2 x+10$ & $y=10$ & $y=-3 x+69$ \\
\hline
\end{tabular}

Table 1

- Reliability at level of performance $1(-54,164)$ 
- Assurance at level of performance $1(-51,160)$

- Empathy at level of performance $1(-43,161)$

- Friendliness at level of performance $1(-39,157)$

- Queue time at level of performance $1(-29,84)$

Table 2

- Number of contacts at level of performance $1(-58,166)$

- Query resolution time at level of performance $1(-59,164)$

- Empathy at level of performance $1(-43,109)$

- Reliability at level of performance 1 and $2(-42,91 ;-42,126)$

- Queue time at level of performance $2(-42,135)$

- Empathy at level of performance $1(-43,109)$

- Assurance at level of performance 1 and $2(-38,92 ;-29,110)$

Table 3

- Query resolution time at level of performance 1 and $2(-38,84 ;-20,45)$

- Reliability at level of performance 2 and $3(-34,76 ;-32,81)$

- Number of Contacts at level of performance 1 and $2(-32,82 ;-22,56)$

- Empathy at level of performance $2(-27,104)$

- Friendliness at level of performance $2(-19,86)$

- Assurance at level of performance $2(-25,77)$

\section{Table 4}

- Reliability at level of performance 3 and $4(-11,28 ;-22,66)$

- Queue time at level of performance $2(-18,66)$

- Empathy for level of performance 1 and $2(-7,22 ;-14,64)$

- Friendliness at level of performance 1 and $2(-13,34 ;-7,55)$

- Assurance at level of performance 2 and $3(-8,35 ;-11,38)$

2) Positive slope with Negative Y-intercept indicates, a strong increase in number of people responding at a particular level of performance for an attribute.

Table 1

- Reliability at level of performance $2(68,-34)$

- Empathy at level of performance $2(66,-37)$

- Assurance at level of performance $2(65,-31)$

- Friendliness at level of performance $2(65,-35)$

- Query resolution time at level of performance $2(23,-15)$

- Number of contacts at level of performance $2(18,-3)$

Table 2

- Reliability at level of performance 3 and $4(41,-33 ; 12,-10)$

- Assurance at level of performance 3 and $4(24,-12 ; 12,-12)$

- Friendliness at level of performance $3(16,-15)$

- Query resolution time at level of performance $5(25,-18$

- Number of contacts at level $5(14,-9)$

- Empathy at level of performance $3(10,-8)$

\section{Table 3}

- Number of contacts at level of performance $5(33,-14)$ 
- Query resolution time at level of performance $5(33,-2)$

- Reliability at level of performance 4 and $5(30,-16 ; 20,-14)$

- Assurance at level of performance $4(16,-4)$

\section{Table 4}

- Number of contacts at level of performance $4(15,-9)$

- Empathy at level of performance $5(12,-8)$

- Queue time at level of performance $5(10,-4)$

- Friendliness at level of performance $5(6,-4)$

3) Positive slope with Positive Y-intercept indicates an increase in number of people responding at a specific level of performance for an attribute. The positive y-intercept value here would imply that, either a high number of people have responded on both the consecutive levels of performance or the change in number of people (slope value) is very small for an attribute.

Table 1

- Queue time at level of performance 2 and $3(42,23 ; 9,13)$

Table 2

- Queue time at level of performance $3(7,17)$

Table 3

- Empathy at level of performance $3(7,5)$

- Queue time at level of performance $4(6,2)$ Table 4

- Reliability at level of performance $5(24,2)$

- Assurance at level of performance $5(9,1)$

- Friendliness level of performance 3 and $4(2,15 ; 2,7)$

\section{Discussion}

The above data analysis shows that, although the main drivers of customer satisfaction are Number of contacts and Query resolution time, the overall degree of satisfaction, is not always a result of performance on these two attributes. For example, the change in degree of satisfaction from 1 to 2 (Table 1), is a result of decline in number of people responding at level 1 of performance for more personal/softer attributes of quality. Again in Table 2, during change in degree of satisfaction from 2 to 3 (i.e. Very Satisfied to Satisfied), along with there being a decline in number of people responding at level of performance 1 for task-focussed attributes (Number of contacts and Query resolution time), there is a simultaneous rise in number of people responding at lower levels of performance, 3 and 4 for personal/softer service attributes.

The same pattern holds throughout the data. This reinforces the main idea behind our hypothesis that, although, customer satisfaction may be governed by a couple of key drivers (Number of contacts and Query resolution time in this case), but the overall degree of satisfaction achieved, is a function of performance on all attributes. Therefore, a customer does not hold the importance of a service attribute as constant, but it's psychological value is dependent upon performance on the attribute itself, as well as the other service attributes, that form 
the current context.

\section{Conclusions}

The current study demonstrates that for customer satisfaction surveys to render maximum benefit, their analysis must achieve the closest possible semblance to the psychological processes that underlie customer evaluations of satisfaction. A guiding premise for this paper has been that customer satisfaction is an aggregate of several emotions. The findings from this study indicate that differentiating the customer satisfaction construct, according to how customers perceive its different levels/degrees, has value with regards to customers' future behaviour towards the company. For example, [25], discovered at Xerox that, its "totally satisfied" customers were six times more likely to repurchase Xerox products than "merely satisfied" customers, and although, "totally satisfied" only ranked two scale points higher than "merely satisfied" in the survey, it generated six times more loyalty.

This study also proves that, although "the managerial uses of the expectancyvalue model rest on its validity as a representation of attitude formation and change" [17], the theoretical underpinnings of the expectancy-value model have not been thoroughly probed to ascertain its usefulness. Despite the fact that a variety of evidence within psychological research proposes non-linear models of human judgement [26], the expectancy-value model proposes a linear relationship between overall customer satisfaction and attributes of quality. Of course, the linearity assumption has been able to gain traction because of reification of statistical models, which simplify human perception and gloss over discrepancies in part of the data. However, as [18] explain, such discrepancies can often provide important clues to the underlying psychological processes.

[27] refers to this issue in acknowledging that often managers and academics apply models derived from behavioural psychology in consumer research "without appreciating either the evolution or the logical application constraints of that model". [28] recognises this deficiency as being symptomatic of the problems associated with functional models of attribute-performance and customer satisfaction relationships in extant literature. It is therefore imperative, that researchers back-track, and revisit the process of attitude acquisition, on which the current models of customer satisfaction are based.

These findings are quite revelatory in understanding the construct of customer satisfaction as it is formed in a customer's mind. From an academic perspective, the main contribution of this study is in demonstrating the importance of a deconstructive approach to analysis of customer satisfaction surveys, that is more revealing of the process by which satisfaction judgements are formed and therefore more useful, as compared to the traditionally deployed reliability based techniques. Although, the study replicates what has been well established in seminal work on personality impression formation, still this is the first instance of these theories having been proven in the study consumer behaviour. 
Considering that the primary purpose of customer satisfaction measurement is to understand the process of how consumers form the satisfaction attitude, the current study provides, a more in-depth understanding of how satisfaction judgements are formed and how practitioners can derive best benefits out of analysing consumer data. However, the main constraint of this study is that it has been conducted in a specific context of call centre customers only. Future research may be able to extend evidence by using the same analytics process in different service settings.

\section{Conflicts of Interest}

The author declares no conflicts of interest regarding the publication of this paper.

\section{References}

[1] Wright, P.L. (1973) Analyzing Consumer Judgement Strategies: Paradigm, Pressures and Priorities. Faculty Working Paper No. 94, University of Illinois, IL.

[2] Asch, S.E. (1946) Forming Impressions of Personality. The Journal of Abnormal and Social Psychology, 41, 258-290. https://doi.org/10.1037/h0055756

[3] Fishbein, M. and Azjen, I. (1975) Belief, Attitude, Intention, and Behaviour, an Introduction to Theory and Research. Addison-Wesley, Boston, MA.

[4] Oliver, R.L. (1980) A Cognitive Model of the Antecedents and Consequences of Satisfaction Decisions. Journal of Marketing Research, 17, 460-469. https://doi.org/10.1177/002224378001700405

[5] Parasuraman, A., Zeithaml, V.A. and Berry, L.L. (1988) SERVQUAL: A Multiple-Item Scale for Measuring Consumer Perceptions of Service Quality. Journal of Retailing, 64, 12-40.

[6] Busacca, B. and Padula, G. (2005) Understanding the Relationship between Attribute Performance and Overall Satisfaction: Theory, Measurement and Implications. Marketing Intelligence \& Planning, 23, 543-561. https://doi.org/10.1108/02634500510624110

[7] Danaher, P.J. (1997) Using Conjoint Analysis to Determine the Relative Importance of Service Attributes Measured in Customer Satisfaction Surveys. Journal of Retailing, 73, 235-260. https://doi.org/10.1016/S0022-4359(97)90005-1

[8] Wilkie, W.L. and Pessemier, E.A. (1973) Issues in Marketing's Use of Multi-Attitude Models. Journal of Marketing Research, 10, 428-441. https://doi.org/10.1177/002224377301000411

[9] Bolton, R.N. and Drew, J.H. (1991) A Multi-Stage Model of Customer's Assessments of Service Quality and Value. Journal of Consumer Research, 17, 375-384. https://doi.org/10.1086/208564

[10] Huang, R. and Sarigöllü, E. (2008) Assessing Satisfaction with Core and Secondary Attributes. Journal of Business Research, 61, 942-949. https://doi.org/10.1016/j.jbusres.2007.10.003

[11] Anderson, N.H. (1970) Functional Measurement and Psychophysical Judgment. Psychological Review, 77, 153-170. https://doi.org/10.1037/h0029064

[12] Birnbaum, M.H. (1972) Morality Judgments: Tests of an Averaging Model. Journal of Experimental Psychology, 93, 35-42. https://doi.org/10.1037/h0032589 
[13] Birnbaum, H.M., Parducci, A. and Gifford, K.R. (1971) Contextual Effects in Information Integration. Journal of Experimental Psychology, 88, 158-170. https://doi.org/10.1037/h0030880

[14] Birnbaum, M.H. (1973) The Devil Rides again: Correlation as an Index of Fit. Psychological Bulletin, 79, 239-242. https://doi.org/10.1037/h0033853

[15] Birnbaum, M.H. (1974) The Nonadditivity of Personality Impressions. Journal of Experimental Psychology, 102, 543-561. https://doi.org/10.1037/h0036014

[16] Rikeyz, R.D. and Birnbaum, M.H. (1974) Compensatory Effects in Moral Judgement: Two Rights Don't Make Up for a Wrong. Journal of Experimental Psychology, 103, 171-173. https://doi.org/10.1037/h0036892

[17] Anderson, T. and Birnbaum, M.H. (1976) Test of an Additive Model of Social Inference. Journal of Personality and Social Psychology, 33, 655-662. https://doi.org/10.1037/0022-3514.33.6.655

[18] Anderson, H.A. and Shanteau, J. (1977) Weak Inferences with Linear Model. Psychological Bulletin, 84, 1155-1170. https://doi.org/10.1037/0033-2909.84.6.1155

[19] Mellers, A.B. and Birnbaum, M.H. (1982) Loci of Contextual Effects in Judgment. Journal of Experimental Psychology, 8, 582-601. https://doi.org/10.1037//0096-1523.8.4.582

[20] Kotler, P. and Keller, K.L. (2005) Marketing Management. 12th Edition, Prentice Hall, Upper Saddle River, NJ, 15-23.

[21] Stauss, B. and Neuhaus, P. (1997) The Qualitative Satisfaction Model. International Journal of Service Industry Management, 8, 236-249. https://doi.org/10.1108/09564239710185424

[22] Driver, C. and Johnston, R. (2001) Understanding Service Customers: The Value of Hard and Soft Attributes. Journal of Service Research, 4, 130-139. https://doi.org/10.1177/109467050142005

[23] Fehr, B. and Russell, J.A. (1984) Concept of Emotion Viewed from a Prototype Perspective. Journal of Experimental Psychology: General, 113, 464-486. https://doi.org/10.1037//0096-3445.113.3.464

[24] Marr, B. and Neely, A. (2004) Managing and Measuring for Value: The case of call centre performance. Cranfield School of Management, Fujitsu.

[25] Jones, T.O. and Sasser Jr., W.E. (1995) Why Satisfied Customers Defect. Harvard Business Review, 73, 88-99.

[26] Dougherty, M.R. and Thomas, R.P. (2012) Robust Decision Making in a Nonlinear World. Psychological Review, 119, 321-344. https://doi.org/10.1037/a0027039

[27] Wright, P.L. (1973) The Cognitive Processes Mediating Acceptance of advertising. Journal of Marketing Research, 10, 53-62. https://doi.org/10.1177/002224377301000108

[28] Reynoso, J. (2010) Satisfaction: A Behavioural Perspective on the Consumer. Emerald Group Publishing Limited, Armonk, New York. 


\section{Appendix: Survey Questionnaire and Variable Names}

\section{Independent Variables}

Q.1 How many times did you have to contact customer service before your query was resolved, number of contacts?
1) Once
2) Twice
3) Thrice
4) More than thrice
5) Query still not resolved

Q.2 How much time did it take for you to get through to customer support agent (queue time)?
1) Immediately
2) 1 - 2 minutes
3) 2 - 4 minutes
4) 4 - 6 minutes
5) More than 6 minutes

Q.3 How much time did it take for the query to your query to be resolved (query resolution time)?
1) Immediately
2) Within 2 week
3) Within 4 weeks
4) More than 4 weeks
5) Query still not resolved

Q.4 Friendliness and professionalism of the agent throughout the call (friendliness)
1) Completely satisfied
2) Very satisfied
3) Satisfied
4) Dissatisfied
5) Very dissatisfied

Q.5Agent listened and understood reasons for the query (empathy)?

1) Completely satisfied

2) Very satisfied

3) Satisfied

4) Dissatisfied

5) Very dissatisfied

Q.6Agent appeared knowledgeable and confident (assurance)?

1) Completely satisfied 
2) Very satisfied

3) Satisfied

4) Dissatisfied

5) Very dissatisfied

Q.7Agent was able to help you understand and provide a solution to your request (reliability)?

1) Completely satisfied

2) Very satisfied

3) Satisfied

4) Dissatisfied

5) Very dissatisfied

\section{Dependent variable}

Q.8 What is your overall satisfaction with the call handling experience (overall customer satisfaction)?

1) Completely satisfied

2) Very satisfied

3) Satisfied

4) Dissatisfied

5) Very dissatisfied 